Artigo recebido em 05/08/2014

Aprovado em 22/09/2014

\section{ISABEL CRISTINA}

CLAVELIN DA

ROSA

Universidade de Brasília belclavelin@gmail.com Doutoranda do Programa de Pós-graduação em Comunicação da Faculdade de Comunicação da Universidade de Brasília e professora de Jornalismo e Publicidade na Universidade Católica de Brasília

\title{
Imprensa Negra: descobertas para o Jornalismo brasileiro
}

\author{
Isabel Cristina Clavelin da Rosa
}

\begin{abstract}
Resumo
Vinte e cinco anos após o surgimento da atividade jornalística no Brasil, em 1808, a imprensa negra iniciava a sua operação por meio do jornal O Homem de Cor, editado por Francisco de Paula Brito, em 1833. Produções jornalísticas feitas para negros e sobre negros, os jornais da imprensa negra representam a conquista de enunciação própria da comunidade negra num período de tempo compreendido da escravização ao terceiro milênio. Neste artigo, é recuperada parte dessa trajetória, aportando novos elementos aos estudos sobre o Jornalismo brasileiro.

Palavras-chave

Mídia e racismo, Imprensa e relações raciais, Jornalismo, Igualdade racial.
\end{abstract}

\begin{abstract}
Twenty-five years after the emergence of journalism in Brazil in 1808, the black press began its operation by means of newspaper O Homem de Cor, edited by Francisco de Paula Brito in 1833. Journalistic productions made for blacks and about blacks, the newspapers of the black press (BLACK PRESS NEWSPAPERS) represent the conquest of the enunciation of the black community in a time period of enslavement to the third millennium. In this article, part of this trajectory is recovered, bringing new elements to studies on Brazilian Journalism.
\end{abstract}

Keywords

media and racism, media and race relations, journalism, racial equality.
Estudos em Jornalismo e Mídia

Vol. 11 No 1 Julho a Dezembrode 2014

ISSNe 1984-6924 
1- Brevíssimo perfil biográfico traçado por Camargo (1987, p.41):

"adquiriu com sacrifício e a prazo, a loja de encadernação e livros do primo Silvino José de Almeida, na praça da Constituição, no 21 (hoje Tiradentes) $e$, acrescentando-lhe tipografia, tornouse o primeiro editor do País, e a sua tipografia o ponto de reunião de intelectuais".

2- Grifo no original.

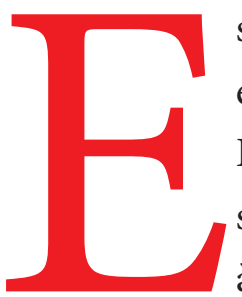

ste artigo aborda a relação entre imprensa e racismo no Brasil por meio da reflexão sobre as produções voltadas à temática racial negra $\mathrm{e}$ a inserção dos negros no jornalismo. Recompõe a trajetória da imprensa negra, apresentando outras possibilidades na reflexão acadêmica sobre o jornalismo brasileiro.

Ao estudar a institucionalização do Jornalismo no Brasil, a jornalista Lavina Madeira Ribeiro constata que o Jornalismo político antecedeu o Jornalismo literário, que, por sua vez, "cresceu juntamente com o Jornalismo noticioso fundado em critérios discursivos internos e bases econômicas de auto-sustentação" (RIBEIRO, 2004, p.118). A autora observa que o Jornalismo político dinamizou a esfera pública durante o século XIX, "comportando-se, muitas vezes, como exclusivo instrumento do fazer político", quando produções jornalísticas apareciam para "operar numa área institucional própria, ancoradas em critérios internos de noticiabilidade e de opinião" (RIBEIRO, 2004, p.118). É entre as produções emergentes interessadas em "operar numa área institucional própria” (IDEM, IBIDEM) que se situa a imprensa negra.

Conforme Oswaldo de Camargo (1987, p.42), "foi Francisco de Paula Brito", em 1833, o precursor da Imprensa Negra $^{2}$, cujos primeiros títulos, pelo menos em São Paulo, só iriam aparecer em 1911, com A Pérola, seguida pouco depois por $O$ Menelick e A Princesa do Oeste". No mesmo reconhecimento histórico, Camargo é implacável ao enumerar as credenciais de Paula Brito para a história brasileira, como o "iniciador do movimento editorial no
Brasil" e um dos "precursores do conto no Brasil” (CAMARGO, 1987, p.42). Entre seus múltiplos talentos e habilidades, estava o revezamento entre as funções de poeta e tradutor.

Como assinala Camargo, a

publicação de O Homem de Cor (Rio de Janeiro, 'Tipografia Fluminense \& Cia, 1833), com o título alterado a partir do $3^{\circ}$. número para $O$ Mulato ou o Homem de Cor, e que circulou de 14 de setembro a 4 de novembro de 1833, altera a data do início da Imprensa Negra, que teria seus primórdios nos fins do século passado. Foi - refere Eunice Ribeiro Gondim, biógrafa de Paula Brito - 'o primeiro jornal brasileiro dedicado à luta contra os preconceitos de raça' (CAMARGO, 1987, p.41).

Inseriu-se, assim, num campo de debates de ideias e conflitos raciais antes mesmo do início das produções jornalísticas da imprensa abolicionista, imbuídas da causa da libertação de africanos e seus descendentes escravizados - estas situadas por alguns autores no período de 18801888, embora Silva (1988) perceba indícios em 1833, em Pernambuco, no Jornal Folha de Recife. Aqui é feita apenas uma conexão histórica, pois as diferenciações entre a imprensa abolicionista e a imprensa negra são altamente perceptíveis. Enquanto a primeira demandava o fim da escravização de negros e negras, muitas vezes de forma gradual e lenta, a segunda reivindicava a liberdade com integração social.

$\mathrm{O}$ pesquisador e poeta negro gaúcho Oliveira Silveira (2005) também situa, no século XIX, o nascimento da imprensa negra no Brasil a partir do jornal $O$ Homem de Cor, de 1833, editado por Francisco de Paula Brito. Juntamente com o Grupo Palmares (CAMPOS, 2006), 
foi Oliveira Silveira que fixou a data de assassinato de Zumbi dos Palmares, iniciando, em 1971, em Porto Alegre, uma série de comemorações que originaram o Dia da Consciência Negra, em 1978, pelo MNUCDR (Movimento Negro Unificado contra a Discriminação Racial).

\section{Jornais negros no século XIX}

A jornalista negra Ana Flávia Magalhães Pinto (2006), baseada em registros históricos, salienta que no ano de 1798 já circulavam em Salvador manifestos e boletins fixados em áreas de grande circulação da cidade no processo de organização da Revolta dos Búzios, mais conhecida como Revolta dos Alfaiates. Contudo, reconhece o jornal O Homem de Cor como o pioneiro da imprensa negra. Outros títulos sucederam-no: Brasileiro Pardo, O Cabrito, O Crioulinho e O Lafuente - todos circulantes em 1833. Fora da Corte (Rio de Janeiro), O Homem - Realidade Constitucional ou Dissolução Social foi o primeiro impresso a circular em Recife (1876), seguido por A Pátria, em São Paulo (1889), e O Exemplo, em Porto Alegre (1892).

Com base nos levantamentos estabelecidos, constata-se o nascimento de um discurso e de uma prática jornalística negra não disseminadora dos estigmas raciais percebidos na imprensa do século XIX e XX e, sim, comprometida com o valor máximo republicano: a igualdade de direitos. Desde 1833, os jornais negros frisavam os direitos constitucionais dos cidadãos brasileiros para ilustrar o grau de exclusão e discriminação que atingia os descendentes de africanos.

Os jornais da imprensa negra do século XIX foram a expressão real de que "os afrobrasileiros conseguiram formular uma fala própria ${ }^{3}$ e torná-la pública ${ }^{4}$. Ainda que não tenham alcançado simultaneamente todo o território nacional, esses impressos são parte do esforço coletivo de controlar os códigos da dominação e subvertê-los" (PINTO, 2006, p.70). Estavam inseridos, por conseguinte, na luta contra o racismo, a discriminação e o preconceito racial no Brasil. Nesse sentido, o conceito de imprensa negra está relacionado ao que Sartre (1968, p.101) denomina "curtoscircuitos da linguagem", porque "não é, pois, só o propósito de negro no sentido de se pintar a si mesmo, mas sua maneira peculiar de utilizar os meios de expressão de que dispõe".

Van Dijk (1997, p.21) assinala que "el control de pensamiento" decorre do acesso aos meios de produção de discurso público e do "control de la acción comunicativa" numa estrutura de poder. No caso da imprensa negra, esses aspectos dimensionam melhor a postura refratária da imprensa em abarcar as discussões de interesse dos negros brasileiros, ou seja, o combate ao racismo e a integração dos negros no projeto de desenvolvimento do Brasil. Essa posição editorial ideológica fez com que os negros criassem outra via de produção jornalística, isto é, um sistema comunicativo onde essas questões pudessem ser abordadas, para desconstrução do "racismo mediatizado" praticado pela imprensa. Trata-se, sem dúvida, de uma estratégia política de interferir na esfera pública na busca pelo poder de influência e emissão de opinião própria, no sentido de participação política, e de travar uma luta ideológica através da imprensa negra contra "la reproducción del racismo" por meio "de los medios de comunicación" (VAN DIJK, 1997, p.73).
3- Grifo da autora.

4- Grifo da autora. 
$\mathrm{Na}$ gráfica de Paula Brito foram impressas diversas obras de consagrados escritores brasileiros, páginas que entraram para a história sem o devido crédito de reconhecimento público para seu editor. Na Tipografia Fluminense \& Cia, de Paula Brito, foram impressos livros de Machado de Assis [Ela (1855), Queda que as mulheres têm pelos tolos (1861) e Desencantos (1861)], Martins Penna [O Juiz de Paz na Roça (1842) e A Família e a Festa na Roça (1842)], Casimiro de Abreu [As Primaveras (1859)], Gonçalves de Magalhães [Antônio José ou o Poeta e a Inquisição (1839) e A Confederação dos Tamoios (1856)], Teixeira de Souza [O Filho do Pescador (1843)] e José Maurício Nunes Garcia Filho [Mauricinas (1851)].

Em Recife, O Homem - Realidade Constitucional ou Dissolução Social apresentava-se, em 1876, como outro legítimo representante da imprensa negra (PINTO, 2006), dissociado o pertencimento do jornal do movimento abolicionista. De acordo como o próprio jornal, esteera "defensor ${ }^{6}$ das pessoas de cor" e profundamente imbuído da causa negra, a exemplo da seção Galeria de Homens de Cor, a qual na primeira edição reservava o culto à memória de Antonio Pereira Rebouças. Contundente em seu conteúdo editorial e alinhado às reivindicações políticas de direitos dos negros, O Homem - Realidade Constitucional ou Dissolução Social circulou até 30 de março de 1876, com o total de 12 números.

Na primeira edição, destaca-se o trecho que conclama ao uso da comunicação para denúncia dos atos discriminatórios e da opressão racial, por meio do explícito oferecimento das páginas do jornal para 6- Grifo da autora. registrou a realização de reuniões políticas, sendo que uma delas teve a participação de cerca de 50 mulheres negras.

Criar um jornal é inserir-se na esfera de poder do Jornalismo de produzir discursos jornalísticos (MARCONDES FILHO, 1989) e de participar da circulação de ideias numa esfera pública, partindo da afirmação pública de opiniões e informações. Isto é, de partes integrantes de um jogo em que estão implícitas relações de dominação, com valor, poder e status.

Nesse sentido, é inevitável a reflexão acerca do papel político de um jornal na sociedade. Conforme Marcondes Filho (1989, p.11), essa é uma maneira "de se dar eco às posições das pessoas, de classe ou de nações através de um complexo industrialtecnológico, que além de preservar suporta impessoalidade, afirma-se, pelo seu poder e soberania, como 'a verdade".

O pesquisador lembra que numa sociedade de classes os interesses políticos podem se sobrepor ao princípio de estimular a circulação de ideias e posições na sociedade, tendo em vista que as forças hegemônicas têm o objetivo de "divulgar fatos que interessam à classe ou a setores dominantes" e de "moldá-los, esticá-los e comprimi-los, reproduzir assim a vida pública e privada conforme os parâmetros ideológicos de seus produtores" (MARCONDES FILHO, 1989, p.51).

De acordo com Lavina Madeira Ribeiro (2004), jornais de maior circulação conseguiam reunir nomes com notoriedade pública e representar uma diversidade de interesses e expectativas no meio urbano. Todavia, essa realidade que começava a se instaurar, especialmente a partir de 1876, "era incompatível com a noção herdada por muitos jornalistas 
sobre a necessária função política e crítica da imprensa" (RIBEIRO, 2004, p.126). Nesse panteão, podem-se inserir Luiz Gama, José do Patrocínio, José Correia Leite e Lino Guedes.

No Sul do Brasil, a imprensa negra teve como representante inicial o jornal $O$ Exemplo, que circulou com interrupções no período de 1892 e 1930. É caracterizado por Silveira (2005, p.115) como "iniciativa $e$ organização de negros ${ }^{7}$. Antecipa-se à importante imprensa negra paulista e paulistana: O Baluarte, Campinas em 1903, A Pérola, São Paulo, 1911, O Menelick, a seguir, O Clarim da Alvorada, mais adiante". Entre os títulos relacionados por Silveira (2005) na imprensa negra gaúcha do século XIX estão: $A$ Cruzada (Pelotas, 1905), A Alvorada (Pelotas, 1907), A Revolta (Bagé, 1925), A Navalha (Santana do Livramento, 1931).

No pioneiro O Exemplo, um estudioso (MORAES, 2002) identifica a presença de poesias de autores brancos, no período 1916-1930 - informação que coloca em xeque possíveis interpretações de uma imprensa negra hermética numa eventual confusão do significado de afirmação de um espaço identitário. Na primeira edição de O Exemplo - editado em Porto Alegre, em 11 de dezembro de 1892 -,a missão do jornal é apresentada à sociedade gaúcha. $\mathrm{O}$ tom reivindicatório e de afirmação da identidade negra apresentado em $O$ Exemplo bradava pela participação social e o fim do racismo e do preconceito racial que impediam os negros de desempenharem o mesmo papel que os brancos na sociedade sul-rio-grandense. O jornal desempenhava uma função social de denúncia e proposição de uma nova ordem social em que negros e brancos pudessem partilhar os mesmos espaços, no mundo real e no mundo simbólico, a exemplo do que preconiza Sartre (1968, p.11): "a ação do negro é antes de tudo ação sôbre si”.

Em História da imprensa no Brasil, Nelson Werneck Sodré (1999) refere-se à imprensa negra através dos jornais $O$ Crioulo, O Crioulinho, O Mulato, O Cabrito e O Homem de Cor como publicações surgidas das "inquietações geradas em três séculos de domínio colonial sob a rígida estrutura do latifúndio" (SODRÉ, 1999, p.157). Quando compreendido o contexto em que o racismo e as desigualdades raciais se operacionalizam, a produção da imprensa negra cresce em importância e significado frente ao poderio ideológico, cultural, político e econômico ao qual se contrapõe.

Conforme Cremilda Medina (1988, p.51), uma "imprensa politicamente militante é, então, mero reflexo de uma situação efervescente. $O$ interesse principal dos jornais é, antes de informar, formar opiniões". Nesse sentido, a incessante produção da imprensa negra no período de 1833-2010 ganha e relevância para os estudos da imprensa brasileira e do Jornalismo, em particular.

\section{Projetos Editoriais no Pós- Abolição}

$\mathrm{Na}$ historicização da imprensa negra paulista, no período de 1915 a 1963, a antropóloga Miriam Nicolau Ferrara considera que a imigração europeia e a rejeição da população negra para um estrato abaixo dos imigrantes foram alguns fatores impulsores para o surgimento dos jornais negros - ponto que a revisão histórica remete para 1833, com o jornal $O$ 
Homem de Cor -, e a sua "concentração no Sul do Brasil, especialmente no Estado de São Paulo" (FERRARA, 1981, p.198).

A partir de sua dissertação de mestrado A imprensa negra em São Paulo, Miriam Ferrara chega a classificar 56 jornais estudados. Entre os quais, destacam-se: no primeiro período, de 1915 a 1923, O Menelik (1915), A Rua (1916), O Xauter (1916), O Alfinete (1918), O Bandeirante (1919), A Liberdade (1919), A Sentinela (1920), O Kosmos (1922) e Getulino (1923); no segundo período, de 1924 a 1937, O Clarim da Alvorada (1924), Elite (1924), Auriverde (1928), O Patrocínio (1928), Progresso (1928), Chibata (1932), Evolução (revista 1933), A Voz da Raça (1933), Tribuna Negra (1935) e A Alvorada (1936); e, no terceiro período, de 1945 a 1963, Alvorada (1945), Senzala (revista 1946), União (1948), Mundo Novo (1950), Quilombo(revista 1950), A Voz daNegritude (1953), O Novo Horizonte (1954), Notícias de Ébano (1957), O Mutirão (1958), Hifen (1960), Níger (revista 1960), Nosso Jornal (1961) e Correio d'Ébano (1963).

Ferrara (1981) concebe entre as características comuns dos jornais negros no primeiro período da imprensa negra paulista a abordagem cotidiana da comunidade negra (versos, notas festivas e amenidades), no sentido de "controle sobre o grupo" (FERRARA, 1981, p.200). Havia matérias de conteúdo reivindicatório, embora reduzidas, haja vista que "começava a formação de uma consciência de grupo". Na segunda fase referida por Ferrara (2005, p.201), “as reivindicações ganham força e a imprensa negra atinge seu ápice", pois o "problema do negro é para, com mais força, o negro reivindicar seus direitos e reclamar sua participação na sociedade ${ }^{9 "}$. Os jornais da imprensa negra passaram a ser o canal de comunicação no qual o "protesto se faz ouvirlo em diferentes aspectos da sua vida tanto no campo profissional, no político, como no lazer". No terceiro período, Ferrara (1981, p.204) verifica que a imprensa negra procurava "reunir os negros que haviam se dispersado, conscientizá-los e reivindicar a participação sócio-política e econômica” e estava comprometida com "o esforço de unir os negros em favor de uma causa comum".

Também jornalista negro com atuação na grande imprensa - nos jornais Última Hora e Correio Paulistano -, Clóvis Moura (2002) relaciona mais de 30 títulos, até a década de 1960, desde o jornal O Menelick, em São Paulo, em 1915. Autointitulado "noticioso, literário e crítico dedicado aos homens de cor" (MOURA, 2002, p.8), O Menelick trazia em sua edição de $1^{\circ}$ de janeiro de 1916 a saudação ao novo ano, contos, poesias, anúncios, notas sociais de nascimentos, casamentos e óbitos, concurso de beleza negra "bem entendido, entre a 'classe"' (MOURA, 2002, p.8).

Como exposto, desde o seu surgimento, em 1833, a imprensa negra e os jornais negros estavam inseridos na luta contra o racismo, a discriminação e o preconceito racial no Brasil. Essa origem e tais características são fundamentais para o entendimento não somente da imprensa negra, mas também para a compreensão da imprensa brasileira. Pois, é a imprensa negra parte integrante da imprensa brasileira e sua existência tem potencial colaborativo para a reflexão sobre a presença e os efeitos do racismo 
na imprensa brasileira, em particular na grande imprensa.

Abdias do Nascimento (2009), que entre as suas múltiplas atuações - como senador da República, secretário de Estado, produtor cultural, professor, pintor, poeta, e, sobretudo, ativista do Movimento Negro -, também foi jornalista da grande imprensa e da imprensa negra, relatou a sua trajetória no jornal $O$ Quilombo, de 1950:

Fui fundador de $O$ Quilombo, que existiu por dez números. O propósito do jornal era envolver cada vez mais a própria comunidade e fazê-la participar de todo o movimento do jornal. Mas acontece que os recursos eram muito pequenos, assim que as tiragens do jornal e o raio de influência dele era muito pequeno. Quase não tinha meios para tirar uma grande tiragem do jornal. (...) Era um grande esforço, porque nós todos éramos pobres trabalhadores. Não tínhamos dinheiro para sustentar o jornal. Num período era revisor de jornal. No outro período, eu era repórter, assim sempre em funções de ganho pequeno (NASCIMENTO, 2009 In: ROSA, 2011, p. 65).

Em consonância com o tema desta pesquisa, a autora perguntou a Abdias do Nascimento (2009) sobre as diferenças entre a grande imprensa e a imprensa negra, especialmente no fazer jornalístico e na produção da notícia em cada uma:

Na imprensa normal, a grande como você diz, a notícia sobre questões negras era esporádica, era de vez em quando. Para publicar, para sair, era preciso um grande empenho junto a secretário do jornal, ao diretor mesmo. E no outro jornal, não. A gente resolvia publicar, dava o destaque que se queria dar. Não tinha ninguém que se opunha, né? (...) Nós conversávamos, assim como estamos conversando nós dois aqui, e cada um fazia aquilo que tinha lá mais familiaridade. Tinha mais conhecimento do assunto, né? Não era um trabalho dividido. Era muita camaradagem, muita amizade. Não tinha assim, tarefas (NASCIMENTO, 2009 In: ROSA, 2011, p. 66).

A imprensa negra "feita por negros e para negros ${ }^{10}$ marcou profundamente o pensamento do negro paulista", pois sentiam "a necessidade de um movimento de identidade étnica, e enfrentando as barreiras de uma imprensa branca (grande imprensa) impermeável aos anseios e às reivindicações da comunidade" (MOURA, 1989, p.69). Baseado nos jornais da imprensa negra paulista, Moura (2002, p.9) a considera como uma "imprensa setorizada" com conteúdo restrito sobre a sociedade, a ponto de os negros terem de se informar na "imprensa branca" sobre acontecimentos nacionais e internacionais. Percebe-se, ainda (MOURA, 2002, p.11), como ideias constantes, a ascensão do negro através da escolarização, o "aprimoramento cultural" e o "bom comportamento social".

A imprensa negra reflete como os negros articulam o conceito de raça sobre si, no sentido de transformação positiva da sua representação social e de "uma reviravolta ideológica” (MOURA, 2002, p.11), traduzida por meio da autoafirmação.

Segundo George Reid Andrews ${ }^{11}$ (1998, p.216), "os jornais negros localizados na capital regularmente comentavam incidentes de negros que não eram servidos em bares, hotéis, restaurantes e barbearias nas cidades menores do Estado". Conforme Moura (1989, p.69), a imprensa negra é uma "voz independente ${ }^{12}$ " do negro com marcas profundas no pensamento negro. Pinto (2006, p.24) concebe a
11- O pesquisador (1998, p.202) considera Miriam Nicolau Ferrara como "fonte básica da imprensa negra". Entre as referências cita Roger Bastide (1951) e Clóvis Moura. Informa, ainda, que grande parte dos jornais pesquisados por Ferrara foram doados para a Universidade de São Paulo, e Michael Mitchell, cientista político estadunidense, preparou o microfilme The Black Press of Brasil, que compõe o acervo da Biblioteca Firestone da Universidade de Princeton. 
“imprensa negra como especializada ou segmentada" a exemplo da imprensa feminina, da imprensa abolicionista e da imprensa operária. A dupla de sociólogos Roger Bastide e Florestan Fernandes (1971), ao analisar as relações de brancos e negros em São Paulo, classifica a imprensa negra como "imprensa adicional", por conta do tríplice desdobramento, "como instrumento de reivindicação, de solidariedade e de educação”. Para Bastide, com registrado por Moura em seu estudo crítico, a imprensa negra tinha o propósito "de reivindicação, contra tudo o que seja em detrimento da elevação do brasileiro de cor; de solidariedade, porque somente a união poderá quebrar o preconceito de cor; de educação, porque o preto só subirá com mais instrução e mais moralidade, e com mais confiança no seu próprio valor” (MOURA, 2002, p.10).

$\mathrm{Na}$ imprensa negra paulista, destacamse os jornais $A$ Voz da Raça ao lado de $O$ Clarim da Alvorada, considerados entre "as duas mais importantes publicações por despertar a consciência do negro paulista" (MOURA, 1989, p.71).

Ao traçar A trajetória e perspectivas do movimento negro brasileiro, Amauri Mendes Pereira (2008) registra o engajamento político da equipe do jornal O Clarim da Alvorada que "tentara, em 1929, realizar um Congresso da Mocidade Negra". Tal registro é feito numa das passagens do texto em que o autor afirma que "a organização de momentos e espaços

12-Grifo da autora 13- Um exemplo de organizações negras, as irmandades negras já eram registradas desde a primeira década dos anos 1700 (ANDREWS, 1998). coletivos de troca de impressão e de debates foi uma constante no Movimento Negro Brasileiro". Como registra o jornalista José Correia Leite (1992), que dedicou grande parte da sua vida aos projetos editoriais negros, o objetivo do encontro era fundar um partido negro, no qual os afro-brasileiros pudessem se organizar politicamente, a fim de reivindicar e garantir a isonomia de direitos entre negros e brancos.

No artigo A União dos Homens de Cor: aspectos do movimento negro nos anos 40 e 50, a pesquisadora negra Joselina Silva (2003) registra a fundação da organização homônima em 1943, na cidade de Porto Alegre, a qual cinco anos mais tarde conquistaria entidades filiadas em dez estados brasileiros. Entre o grupo de cinco homens fundadores, havia uma mulher, uma trabalhadora doméstica. No texto, Joselina Silva aborda a importância dos jornais negros brasileiros nas décadas de 1940 e 1950 e de entidades, como a União dos Homens de Cor, na reação ao racismo no Brasil.

\section{Produção Jornalística}

\section{entre 1970-2010}

Outra referência importante da imprensa negra no Brasil é a partir de 1970 (MORAES, 2002; PEREIRA, 2008; FREITAS, 2009), período em que a efervescência afro-brasileira desencadearia processos políticos como a fundação do MNUCDR (Movimento Negro Unificado contra a Discriminação Racial), em 1978, seguindo para a nova formatação de entidades e organizações negras contra o racismo, cujas primeiras expressões são verificadas no processo abolicionista por meio de quilombos, irmandades negras ${ }^{13}$, clubes negros, entre outros (GONZALEZ, 1982). Novamente, Silveira (2005) fornece mais uma referência para o entendimento do papel da imprensa negra no final dos anos 1970: 
Marco inequívoco é Tição, de Porto Alegre (grupo Tição, 1977-1980). Revistas Tição em 1978 e 1979, dois números e a publicação única do jornal Tição em 1980. Apresentação cuidada, boa diagramação e conteúdo envolvendo história, debate sobre racismo, questões sociais, políticas e culturais em geral, reafirmaram a possibilidade de uma imprensa negra vigorosa, renovada, séria e rica em abordagens, temas, profundidade. (...) Tição dialoga com imprensa negra da década: o anterior e clandestino A Árvore das Palavras, Afro-Latino-América (in Versus), Jornegro (...)" (SILVEIRA, 2005, p.115).

Independentemente da curta e intensa vida, como os demais impressos contemporâneos (PEREIRA, 2008), Tição se destaca pela contundente cobertura da temática negra e pela denúncia do racismo. No seu primeiro número, a chamada de capa da revista revela três questões atuais: educação, política e gênero. A saber: "Racismo diz presente na escola", "Escurinho: o negro tem que evoluir politicamente" e "A mulher negra cansou de ser doméstica" (SILVEIRA, 2005). Já a primeira e única edição do jornal, em outubro de 1980, descortina mais temas em franco debate na atualidade, tais como violência racial, discriminação no mercado de trabalho, conjugação das discriminações de gênero e raça e indicadores sociais: "Chega de violência", cuja charge coloca em primeira plano um jovem negro e um cerco de policiais a suas costas, "Igualdade e autonomia do negro", "Negra: discriminada em dose dupla" e "Censo tapa o sol com a peneira". O jornalista negro Paulo Ricardo de Moraes (2002) lembra que a revista Tição teve grande receptividade local e influenciou o surgimento de novas publicações em outras localidades do país.
Segundo o jornalista negro Jorge Roberto Freitas (2009), os anos 1970 representam o ressurgimento das publicações da imprensa negra circulantes até meados de 1960. No estudo crítico sobre Imprensa Negra, de Clóvis Moura (2002), o escritor Oswaldo de Camargo explicita certo pessimismo em relação à existência de uma imprensa negra após os anos 1970 pelo fato de não existir "mais aquele leitor negro altamente receptivo e participante, sócio ou freqüentador de associações ou entidades negras" e face aos novos projetos editoriais comerciais como a revista Raça Brasil, o que poderia receber, de acordo com o pesquisador, o nome de "imprensa negrista" (CAMARGO, 2002, p.4).

Antes da nominação de qualquer outra vertente da imprensa negra, cabe distinguir a natureza dos projetos editorais voltados ao público negro. Algumas iniciativas estão vinculadas a organizações negras contra o racismo, com produções vinculadas ao Movimento Negro, diferenciandose inclusive de ações comunicativas institucionais que objetivam a divulgação institucional; e outras adotam um caráter comercial, percebendo o público negro como consumidor de informação. Talvez essa distinção possibilite uma melhor compreensão do empreendimento da imprensa negra que perpassa os séculos, antes mesmo da Abolição da Escravatura, até os dias de hoje, associado à luta maior que é o enfrentamento do racismo.

Com relação ao conteúdo e a linha editorial dos jornais da imprensa negra, Muniz Sodré (1999, p.240) considera que o "protesto racial" contra o racismo, a discriminação e o preconceito racial estava dentro de um "horizonte político integracionista" e o que o indivíduo negro 
aspirava "tão-só à igualdade econômica e política, acompanhada do respeito racial". A seguir, o pesquisador aborda a especificidade da imprensa negra: "A importância de uma imprensa negra acentua-se quando se leva em consideração que os discursos sociais desempenham um papel central tanto na produção quanto na reprodução do preconceito e do racismo" (SODRÉ, 1999, p. 242).

Cabe aqui lançar questões fundamentais para compreensão do esforço na constituição da imprensa negra e de um Jornalismo comprometido com a temática racial negra, particularmente a problemática racial enfrentada por africanos e seus descendentes na sociedade brasileira. Essas estratégias adotadas pelos afro-brasileiros serviram para combater o racismo no século XIX e XX? A imprensa negra poderia consolidar-se como uma prática jornalística $^{14} \quad$ antirracista? Partindo do ensinamento de Sartre (1968), um racismo antirracista tem o sentido da desconstrução do racismo e não de sua reatroalimentação, como poderia ser confundido.

A imprensa negra se constituiu como um dos instrumentos utilizados pelos negros brasileiros para a provocação de um debate público sobre o racismo

14 - Bourdieu insere a atividade jornalística no centro de disputas $e$ interesses sociopolíticos e culturais: "nesse microcosmo que éo mundo do Jornalismo, são muito fortes as tensões entre os que desejariam defender os valores da autonomia, da liberdade" (1997, p.52).

15- Grifo da autora

16- Grifo da autora

17- Grifos da autora no País, a partir do domínio da técnica jornalística pelos negros e do uso da esfera pública para a enunciação de um discurso dissonante das forças hegemônicas. Como já disse o jornalista Alberto Dines (1986, p.63), "quando um jornal é pequeno, os assuntos proibidos e os nomes malditos são poucos. Isto pode transformá-lo num grande jornal” - esta máxima se aplica ao enfrentamento do racismo empreendido pela imprensa negra. Com seu caráter associativo de tratar a causa negra, a imprensa negra ocupou e ocupa papel decisivo e, por vezes, determinante para a organização política dos negros no enfrentamento do racismo.

Dessa forma, a intensificação do debate racial verificada na reserva de vagas para negros nas universidades, no Estatuto da Igualdade Racial ou na regularização das terras de quilombolas, entre outros temas atuais, demonstra a importância da imprensa negra para a ressignificação de fatos e acontecimentos, tendo em vista a polaridade do noticiário e da opinião pública.

Ao referir-se à imprensa negra da década de 1980, Muniz Sodré (1999) verifica a intencionalidade dos jornais negros de "desmontar o mito da democracia racial $^{15}$ brasileira e montar estratégias antirracistas $^{16}$. . No seguinte trecho, ele ressalta esse compromisso da imprensa negra:

A imprensa negra do passado era também política, ainda que não necessariamente partidária: tratava-se de exprimir os anseios ascensionistas ou integracionistas de um grupo social estigmatizado pela cor e pela origem escrava. Era uma imprensa, portanto, impelida pela luta antirracista, ainda que suas estratégias nem sempre tenham-se pautado por posições muito nítidas ou ideologicamente progressistas (SODRÉ, 1999, p.247).

$\mathrm{Na}$ edição número 20, o Jornal do MNU (Movimento Negro Unificado) dava destaque aos 20 Anos do Dia Nacional da Consciência Negra. Reconhecendose como "imprensa negra autônoma, livre e independente ${ }^{18}$, o jornal revela nas edições trimestrais a organização 
política, a mobilização e a solidariedade entre as diversas causas negras (mulheres, quilombolas, por exemplo) e a afirmação da identidade negra em entrevistas, dicas de leitura, poesias e relatos de acontecimentos nacionais sob a perspectiva racial. No número seguinte, em editorial, o Jornal do MNU abordou a questão das comunidades quilombolas.

Ainda na década de 1990, surge o Jornal İrohìn, como decorrência da Marcha Zumbi 300 anos, contra o Racismo, pela Cidadania e a Vida, realizada em $1995^{19}$. A publicação apresenta sua missão com o objetivo de "informar à sociedade sobre assuntosnão tratadospelagrande imprensa ${ }^{20}$ e diretamente relacionados ao cotidiano da comunidade afro-descendente" ${ }^{21}$. Significando notícia em yorubá, o İrohìn em seu primeiro editorial, de maio/junho de 1996, apresentou-se como "organização não-governamental plural, de amplo espectro político e sintonizada com a liderança negra”.

Em entrevista para esta pesquisa, Abdias do Nascimento (2009) fez considerações acerca do conteúdo editorial do Jornal İrohìn, reconhecendo-o como um legítimo representante da imprensa negra por estar intrinsecamente vinculado à luta política dos afro-brasileiros contra o racismo no Brasil:

Acho extraordinário o esforço daquela gente. Acho extraordinário porque é um jornal que tem peso. Ele não perde tempo, ele não perde espaço. Tem um peso mesmo, tem influência. Só publica coisa que tem sentido. Não é brincadeirinha de fazer jornal. Porque já houve muito jornal negro que é só brincadeira, papagaiada. Não tinha nada o que dizer, era mais passatempo. O İrohìn entra na luta política mesmo e faz a notícia pra valer (NASCIMENTO, 2009, In: ROSA, 2011, p, 71).

Pelo exposto, entende-se que o conceito de imprensa negra está relacionado ao que Sartre (1968) denomina como tomada de consciência, "diferente da reimersão em si, trata-se de reconhecer-se na ação e pela ação". A abordagem de Hannah Arendt (2008, p.15) também inspira a pensar a imprensa negra no significado da ação política como "condição humana da pluralidade", pois "todos os aspectos da condição humana têm alguma relação com a política; mas esta pluralidade é especificamente a condição - não apenas a conditio sine qua non, mas a conditio per quan - de toda a vida política".

Desse modo, é salutar retirar a imprensa negra do ostracismo imposto pela história da imprensa brasileira e pelos teóricos da comunicação nacional. Moura já conclamou maior atenção dos cursos de Comunicação por considerar a imprensa negra "pouco conhecida e menos ainda divulgada", além de "não incluída nos programas das escolas de comunicação como capítulo a ser estudado" (MOURA, 2002, p.2). É imperativo refletir criticamente quão tamanha supressão - salvo raras exceções e breves citações como Bahia (1972), Melo (1972) e Werneck (1994) - prestou-se à reiteração do racismo e à prevalência da supremacia branca no pensamento e nos estudos da comunicação, da imprensa e do Jornalismo no Brasil. Ou sobre o epistemicídio como instrumento de dominação racial, como aborda a filósofa negra Sueli Carneiro (2005).

De acordo com Ramon y Cajal (1979, p.14), "não há questões esgotadas senão homens esgotados nas questões", ou, por princípio de equidade de gênero: homens e
18- Lima Júnior (2009) destaca em dissertação de mestrado em Educação da Universidade de São Paulo o caráter educativo da imprensa negra, baseado no estudo de caso do jornal İrohin (19962006).

19- Grifo da autora

20- Informações extraídas do site do Jornal İrohin. Disponível em <http://www. irohin.org.br $>$ Acesso em: 19 set. 2008. 
mulheres esgotadas nas questões. Haveria, por conseguinte, um esgotamento epistemológico desse campo acadêmico, distante de grandiosas questões como a história da imprensa negra e o fazer jornalístico desse segmento altamente especializado e associado ao tema do combate ao racismo e integração do negro à sociedade brasileira.

\section{Considerações finais}

As produções da imprensa negra sinalizam a possibilidade de subversão da falta de interesse epistemológico não somente na história da imprensa negra, mas também na sua capacidade de reivindicação, mobilização social, educação e apreciação das relações humanas entre os grupos raciais brasileiros.

Referem-se, pois, ao que o teórico brasileiro José Marques de Melo entende como engajamento consciente ou não para compreender os instrumentos que os grupos dominantes utilizam e reproduzem para fazer valer a sua visão de mundo.

Essa prática começou a se alterar gradativamente a partir do ingresso de pesquisadores e pesquisadoras interessados em "trabalhos acadêmicos que vislumbram, numa postura crítica, os problemas nacionais de comunicação" e inseridos num campo de análise "não necessariamente coincidente com a das classes dominantes" (MELO, 1980, p.11). Pode-se incorporar neste espectro a produção de um pensamento negro na comunicação, isto é, no contexto das epistemologias do Sul (SANTOS, 2009) e no propósito de agregar, à produção intelectual, o desmantelamento do sistema hegemônico cognitivo que vigora em detrimento da dinâmica e da realidade social, condicionando-as a um sistema de exclusões e discriminações.

\section{Referências bibliográficas}

ANDREWS, George Reid. Negros e brancos em São Paulo (1888-1988). Bauru: Edusc, 1998. ARENDT, Hannah. A condição humana. 10.ed. Rio de Janeiro: Forense Universitária, 2008.

BAHIA, Juarez. Jornal, história e técnica. 3.ed. São Paulo: Ibrasa, 1972.

BASTIDE, Roger. A imprensa negra no Estado de São Paulo. In: Estudos afro-brasileiros.

Boletim de Sociologia, 2. série, n.2. São Paulo: Faculdade de Filosofia, Ciências e Letras da USP, 1951.

BOURDIEU, Pierre. Sobre a televisão. Rio de Janeiro: Jorge Zahar Ed., 1997.

CAMARGO, Oswaldo. O negro escrito. São Paulo: Secretaria de Estado da Cultura, 1987. . O que representa esta reedição de fac-símiles da imprensa negra. In: Imprensa negra: estudo crítico de Clóvis Moura - Edição Fac-Similar. São Paulo: Imprensa Oficial de São Paulo/Sindicato dos Jornalistas de São Paulo, 2002.

CAMPOS, Deivison Moacir Cezar de. O grupo Palmares (1971-1978) - um movimento 
negro de subversão e resistência pela construção de um novo espaço social e simbólico. 196f. Porto Alegre: PUCRS, 2006. Dissertação (Mestrado em História), Pontifícia Universidade Católica do Rio Grande do Sul, 2006.

CARNEIRO, Sueli. A construção do outro como não-ser como fundamento do ser. 340 f. São Paulo: USP, 2005. Tese (Doutorado em Filosofia), FEUSP, Universidade de São Paulo, 2005.

FERNANDES, Florestan. Integração do negro à sociedade de classes. MEC: INEP : Centro Brasileiro de Pesquisas Educacionais: Rio de Janeiro, 1964.

FERRARA, Miriam Nicolau. A imprensa negra paulista (1915-1963). São Paulo: USP, 1981. Dissertação (Mestrado em Antropologia Social), FFLCH, Universidade de São Paulo, 1981.

FERREIRA, Maria Claudia Cardoso. Representações sociais e práticas políticas do movimento negro paulistano - as trajetórias de Correia Leite e Veiga dos Santos (19281937). 224 f. Rio de Janeiro: UERJ, 2005. Dissertação (Mestrado em História), Universidade do Estado do Rio de Janeiro, 2005.

FREITAS, Jorge Roberto. A imprensa negra - a trajetória visível. 1.ed. Rio de Janeiro: CEAP, 2009.

LEITE, José Correia \& CUTI ...E disse o velho militante - depoimentos e artigos. São Paulo: Secretaria Municipal da Cultura, 1992.

LIMA JUNIOR, Ariovaldo. Jornal İrohin - estudo de caso sobre a relevância educativa do papel da imprensa negra no combate ao racismo (1996-2006). 123f. São Paulo: USP, 2009. Dissertação (Mestrado em Educação), Faculdade de Educação, Universidade de São Paulo, 2009.

MARCONDES FILHO, Ciro. O capital social da notícia - jornalismo como produção de segunda natureza. 2.ed. São Paulo: Ática, 1989.

MEDINA, Cremilda. Notícia um produto à venda - jornalismo na sociedade urbana industrial. 2.ed. São Paulo: Summus, 1988.

MELO, José Marques de (org). Comunicação e classes subalternas. São Paulo: Cortez Editora, 1980.

MELO, José Marques de e QUEIROZ, Adolpho (org). Identidade da imprensa brasileira no final de século - das estratégias comunicacionais ao enraizamento e às ancoragens culturais. São Bernardo do Campo: Cátedra UNESCO de Comunicação para o Desenvolvimento Regional: Universidade Metodista de São Paulo, 1998.

MORAES, Paulo Ricardo de. Imprensa negra gaúcha - a voz que não se cala. In: O povo negro no Sul. Associação Riograndense de Imprensa, Porto Alegre, 2002.

MOURA, Clóvis. História do negro brasileiro. São Paulo: Editora Ática,1989. Imprensa negra - estudo crítico de Clóvis Moura - Edição Fac-Similar.

São Paulo: Imprensa Oficial de São Paulo: Sindicato dos Jornalistas de São Paulo, 2002.

NASCIMENTO, Abdias. Entrevista concedida a Isabel Cristina Clavelin da Rosa. Rio de Janeiro, Brasil. 7 de novembro de 2009. In: ROSA, Isabel Cristina Clavelin da Rosa. Racismo em Pauta - A pluralidade confrontada no noticiário da Folha de S. 
Paulo na primeira década de 2000. 241f. Brasília: UnB, 2011. Dissertação (Mestrado em Comunicação), Faculdade de Comunicação, Universidade de Brasília, 2009.

PEREIRA, Amauri Mendes. Trajetória e perspectivas do movimento negro brasileiro. Belo Horizonte: Nandyala editora, 2008.

PINTO, Ana Flávia Magalhães. De pele escura à tinta preta - a imprensa negra no século XIX (1833-1899). 197 f. Brasília: UNB, 2006. Dissertação (Mestrado em História), Instituto de Ciências Humanas, Universidade de Brasília, 2006.

RAMÓN Y CAJAL, Santiago. Regras e conselhos sobre a investigação científica. São Paulo: Edusp, 1979.

RIBEIRO, Lavina Madeira. Imprensa e espaço público - a institucionalização do Jornalismo no Brasil 1808-1964. E-papers: Rio de Janeiro, 2004.

ROSA, Isabel Cristina Clavelin da Rosa. Racismo em Pauta - A pluralidade confrontada no noticiário da Folha de S. Paulo na primeira década de 2000. 241f. Brasília: UnB, 2011. Dissertação (Mestrado em Comunicação), Faculdade de Comunicação, Universidade de Brasília, 2009.

SANTOS, Boaventura de Sousa. Há um racismo insidioso que exige luta dos movimentos sociais de uma maneira que não se pensava antes. Conferência A Reinvenção da Emancipação Social a partir das Epistemologias do Sul, Universidade de Brasília. İrohìn On Line, jul. 2009, reportagem de Isabel Cristina Clavelin da Rosa. Disponível em: <http://www.irohin.org.br/onl/new.php?sec=news\&id=4506>. Acesso em: 3 nov. 2009.

SANTOS, Irene. Negro em preto e branco: história fotográfica da população negra de Porto Alegre. Porto Alegre: Do Autor, 2005.

SARTRE, Jean-Paul. Reflexões sobre o racismo. 5.ed. São Paulo: Difusora Europeia do Livro/Ed. da Universidade de São Paulo, 1968.

SILVA, Joselina. A união dos homens de cor - aspectos do movimento negro dos anos 40 e 50. Estudos Afro-Asiáticos, Rio de Janeiro, n. 2, ano 25, p. 215-235, 2003.

SILVA, Leonardo Dantas. A imprensa e a abolição. Recife: Fundaj:Editora Massangana, 1988.

SILVEIRA, Oliveira Ferreira da. Palavra de negro. In: SANTOS, Irene. Negro em preto e branco: história fotográfica da população negra de Porto Alegre. Porto Alegre: Do Autor, 2005.

SODRÉ, Nelson Werneck. História da Imprensa no Brasil. Rio de Janeiro: Mauad, 1999. SODRÉ, Muniz. Claros e escuros - identidade, povo e mídia no Brasil. Petrópolis: Vozes, 1999.

VAN DIJK, Teun A. Racismo y análisis crítico de los medios. 1.ed. Barcelona: Ediciones Paidós Ibérica, 1997.

Estudos em Jornalismo e Mídia está sob a Licença Creative Commons 2.5 